\title{
Successful treatment with rituximab for central nervous system vasculitis caused by Epstein-Barr virus-associated lymphoproliferative disorder with immunoglobulin $\mathrm{M}$ gammopathy
}

\author{
Juhee Lee ${ }^{1}$, Han Sang Lee ${ }^{1,2}$, Kon Chu ${ }^{1,3}$ \\ ${ }^{1}$ Department of Neurology, Seoul National University Hospital, Seoul National University College of Medicine, Seoul, Korea \\ ${ }^{2}$ Center for Hospital Medicine, Seoul National University Hospital, Seoul, Korea \\ ${ }^{3}$ Comprehensive Epilepsy Center, Seoul National University Hospital, Seoul National University College of Medicine, Seoul, Korea
}

\begin{abstract}
Monoclonal gammopathy of undetermined significance (MGUS) is associated with several autoimmune conditions, including central nervous system (CNS) vasculitis. Epstein-Barr virus (EBV) is a pathogen capable of triggering a systemic immune response and is involved in the occurrence of a wide range of B-cell lymphoproliferative disorders. In systemic autoimmune diseases, EBV infection is suspected to play a central role in pathogenesis. Here, we present a case that was thought to be a systemic autoimmune disease and CNS vasculitis that developed after EBV infection, demonstrating that rituximab is effective for the treatment.
\end{abstract}

Keywords: Epstein-Barr virus, Central nervous system vasculitis, Rituximab, Monoclonal gammopathy of undetermined significance

\section{Introduction}

Monoclonal gammopathy of undetermined significance (MGUS) is an asymptomatic premalignant clonal plasma cell or lymphoplasmacytic proliferative disorder [1]. Annually, approximately $1 \%$ of MGUS transform to multiple myeloma or other related disorders such as B-cell lymphoma, Waldenstrom's macroglobulinemia, or immunoglobulin light chain amyloidosis [2]. The exact etiology of MGUS has not been identified; however, the disease may be associated with several autoimmune conditions, including central nervous system (CNS) vasculitis [3]. Epstein-Barr virus (EBV) has been shown to be involved in the occurrence of a wide range of B-cell lymphoproliferative disorders. EBV infection is suspected to play a central role in the pathogenesis and may contribute to the development of autoimmune disease by increasing the proportion of immune cells with autoimmunity [4]. Similarly, autoimmune disease can occur post EBV infection, but reports on the CNS are still not sufficient. Here, we present the case of a 42-year-old woman with CNS vasculitis associated with monoclonal gammopathy of immunoglobulin M (IgM) kappa type after infection with EBV. After steroid treatment, only a partial effect was shown, but rituximab administration caused immediate and complete remission. Rituximab may be considered as a treatment option for patients suspected of having CNS vasculitis following viral infection, particularly EBV infection.

\section{Case Report}

A 42-year-old woman was admitted to another hospital due to headache and fever that began 7 days prior to admission. The

Received: September 17, 2021 Revised: October 11, $2021 \quad$ Accepted: October 15, 2021

Correspondence: Kon Chu

Department of Neurology, Seoul National University Hospital, 101 Daehak-ro, Jongno-gu, Seoul 03080, Korea

E-mail: stemcell.snu@gmail.com

ORCID: https://orcid.org/0000-0001-5863-0302

Copyright ( 2022 by The Korean Encephalitis and Neuroinflammation Society

This is an open access article distributed under the terms of the Creative Commons Attribution Non-Commercial License (http://creativecommons.org/licenses/by-nc/4.0/) which permits unrestricted non-commercial use, distribution, and reproduction in any medium, provided the original work is properly cited. 
patient had a 10-year history of episodic paresthesia in her fingers and toes when exposed to cold, which was diagnosed as limited systemic sclerosis 3 years before admission. The patient also had a history of recurrent umbilical hernia and pelvic organ prolapse of unknown etiology. Initial cerebrospinal fluid (CSF) analysis revealed pleocytosis of 459 white blood cells $/ \mathrm{mm}^{3}$ (leukocytes $88 \%$; lymphocytes $12 \%$ ), an elevation protein level of $161 \mathrm{mg} / \mathrm{dL}$, and low glucose (36 mg/ $\mathrm{dL}$ ) with positive EBV DNA polymerase chain reaction (PCR) results. The initial magnetic resonance imaging (MRI) showed multifocal patchy T2 high signal intensity in bilateral cerebral hemispheres with hemorrhagic changes (Figure 1A and B). She was treated with intravenous vancomycin (aim for predose level 15-20 mg/L), ceftriaxone (2 g intravenously [IV] every 12 hours), acyclovir (10 mg/kg), and dexamethasone (10 mg IV every 6 hours). Despite receiving antimicrobial treatment based on the meningoencephalitis diagnosis, the patient's headache gradually worsened and her visual field began to blur. She was referred to our hospital for further evaluation after 7 days of antimicrobial treatment.

Upon physical examination, neither the liver nor spleen were palpable in the abdomen, and there was no edema of the lower extremities. Neurological examination revealed a drowsy mentality, general weakness (MRC [Medical Research Council] grade III), and decreased visual acuity to differentiate only hand motion. Vital signs at initial evaluation were: blood pressure, 119/87 $\mathrm{mmHg}$; heart rate, 64 beats/min; respiratory rate, 18 breaths $/ \mathrm{min}$; and temperature, $37.3^{\circ} \mathrm{C}$. In the blood test, the hemoglobin sedimentation rate was $56 \mathrm{~mm} / \mathrm{hr}$, the C-reactive protein was $3.09 \mathrm{mg} / \mathrm{dL}$, serum cryoglobulin was positive, and mild hyponatremia (133 $\mathrm{mEq} / \mathrm{L})$ was observed. Except for the above, no abnormal findings such as anemia were observed in the blood tests. In the complete blood count, leukocytes were $2,660 / \mu \mathrm{L}$, hemoglobin was $8.6 \mathrm{~g} / \mathrm{dL}$, platelets were $213,000 / \mu \mathrm{L}$, mean cell volume was $80.3 \mathrm{fL}$, and mean corpuscular hemoglobin was $23.6 \mathrm{pg}$. Biochemical tests found that the total protein was $10.2 \mathrm{~g} / \mathrm{dL}$, albumin was $3.26 \mathrm{~g} / \mathrm{dL}$, aspartate aminotransferase was $24 \mathrm{IU} / \mathrm{L}$, alanine aminotransferase was $19 \mathrm{IU} / \mathrm{L}$, alkaline phosphatase was 52IU/L, lactic dehydrogenase was $186 \mathrm{IU} / \mathrm{L}$, total bilirubin was $0.6 \mathrm{mg} / \mathrm{dL}$, blood urea nitrogen was $12 \mathrm{mg} / \mathrm{dL}$, and creatinine was 0.89 $\mathrm{mg} / \mathrm{dL}$. Serum electrolytes were $\mathrm{Na} 133 \mathrm{mEq} / \mathrm{L}$, K was 4.4 $\mathrm{mEq} / \mathrm{L}, \mathrm{Cl}$ was $112 \mathrm{mEq} / \mathrm{L}$, total calcium was $8.4 \mathrm{mEq} / \mathrm{L}$, ionized calcium was $4.63 \mathrm{mEq} / \mathrm{L}$, uric acid was $4.3 \mathrm{mg} / \mathrm{dL}$, serum cholesterol was $94 \mathrm{mg} / \mathrm{dL}$, and serum triglyceride was $24 \mathrm{mg} /$ $\mathrm{dL}$; proteinuria was not observed as a result of urinalysis.

CSF analysis was conducted in our hospital and showed 32 white blood cells $/ \mathrm{mm}^{3}$ (leukocytes, 12 cells/ $\mu \mathrm{L}$; lymphocytes, 12 cells $/ \mu \mathrm{L}$; and others, 8 cells $/ \mu \mathrm{L}), 40 \mathrm{red}$ blood cells $/ \mathrm{mm}^{3}$, $138 \mathrm{mg} / \mathrm{dL}$ of protein, and $33 \mathrm{mg} / \mathrm{dL}$ of glucose (serum glucose, $99 \mathrm{mg} / \mathrm{dL}$ ). The opening pressure was normal at $17 \mathrm{~cm}$ $\mathrm{H}_{2} \mathrm{O}$.

No specific antibodies against neuronal cell-surface or synaptic proteins were found in the serum or CSF. In addition, viral PCR in the CSF and serum were all negative, including EBV. Serum protein electrophoresis was normal (total protein, 7.0 g/dL; M-spike, 0\%), but immune-typing results showed a dimmed monoclonal band against the anti-IgM and anti-kappa antiserum suggesting monoclonal gammopathy of the IgM kappa type. There was no evidence of clonal plasma cell infil-

Figure 1 Serial brain magnetic resonance images of the patient
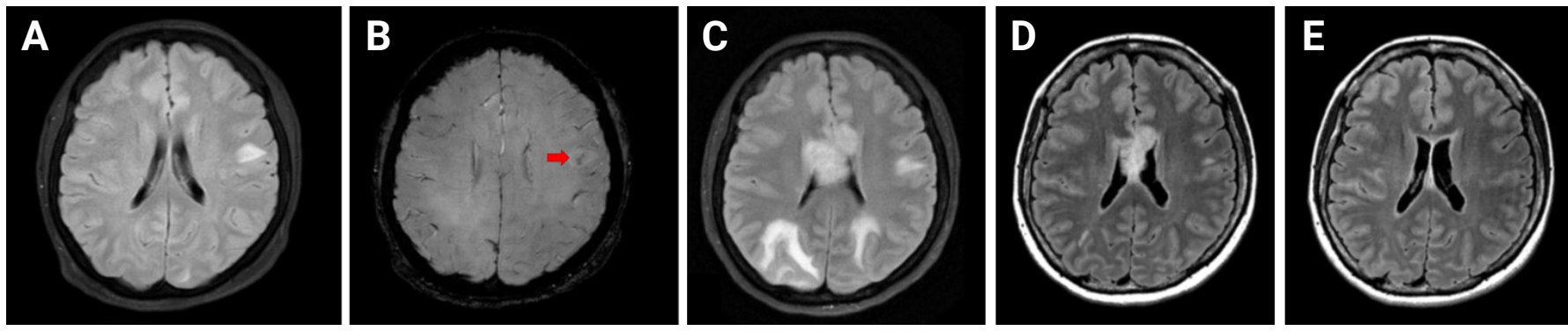

(A) A 4.5-cm patchy T2 high signal intensity (SI) in the left hemisphere. (B) A 4.5-cm size lesion with inner hemorrhagic change transformation on susceptibility-weighted imaging in the same location (red arrow). (C) Interval increased in the extent of multifocal patchy T2 high SI along the bilateral cerebral hemispheres and corpus callosum. (D) Decrease in multifocal patchy T2 high SI along the bilateral cerebral hemispheres and corpus callosum after the 4th cycle of rituximab. (E) Further decrease in multifocal patchy T2 high SI along the bilateral cerebral hemispheres and corpus callosum after the 11th cycle of rituximab. 
tration in bone marrow biopsies. MRI findings showed aggravated multifocal patchy $\mathrm{T} 2$ high signal intensity in bilateral cerebral hemispheres compared with the previous study (Figure 1C). The positron emission tomography scan revealed relatively mild hypometabolic lesions in the left high parietal and right occipital cortices, suggesting CNS inflammation (Figure 2). Conventional angiography showed stenoses of multiple medium-sized brain arteries in the form of beads on string, a typical finding of CNS vasculitis (Figure 3). The patient received a high-dose corticosteroid based on the clinical diagnosis of CNS vasculitis. After steroid administration, visual acuity and motor power recovered quickly, but the patient continued to complain of gait imbalance. Intravenous rituximab $\left(375 \mathrm{mg} / \mathrm{m}^{2}\right)$ was administered at regular intervals (the first four sessions were administered weekly and then monthly thereafter). By the end of the fourth cycle, the patient's clinical symptoms had recovered completely and image findings were improved (Figure 1D). The CSF profile was also improved with 3 white blood cells $/ \mathrm{mm}^{3}$, as well as a normal range of protein $(40 \mathrm{mg} / \mathrm{dL})$ and $62 \mathrm{mg} / \mathrm{dL}$ of glucose (serum glucose, $127 \mathrm{mg} / \mathrm{dL}$ ). Rituximab was maintained on a monthly schedule, and the patient remained symptom-free for over a year. Furthermore, the T2 high signal seen on MRI almost disappeared after the 11th cycle of rituximab (Figure 1E).

\section{Discussion}

We present a case of CNS vasculitis that is presumed to have developed after EBV infection. At first, brain involvement of systemic sclerosis was considered due to past medical history. However, the characteristic brain involvement of systemic

Figure 2 F-18 fluorodeoxyglucose positron emission tomography of the brain
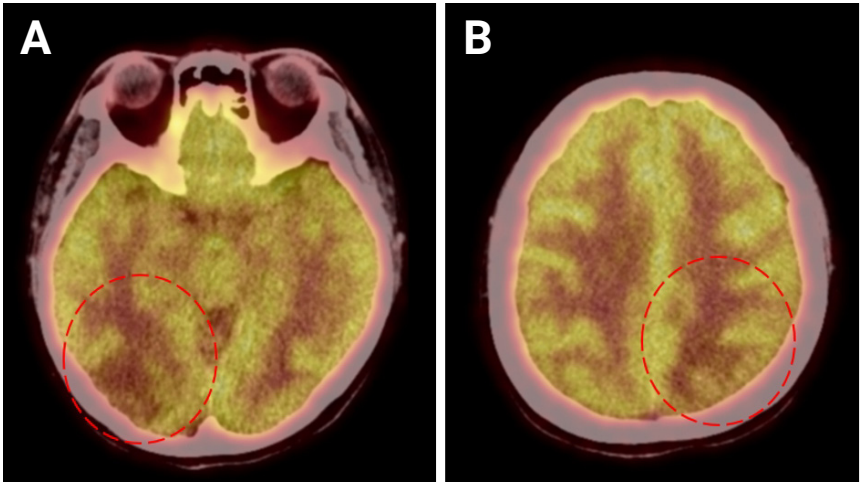

Relatively mild hypometabolic lesions in left high parietal and right occipital cortices (round dotted line). sclerosis, such as small vessel calcification and intracerebral calcification [5], was not observed. Cryoglobulin-related vasculitis was also considered but was excluded after observing that angiography showed the vasculitis invading medium-sized blood vessels and not small blood vessels and because it responded well to steroids [6].

Although the precise etiology of CNS vasculitis is unknown, infectious agents have been proposed as triggers [7]. EBV is a pathogen capable of triggering a systemic immune response, including in the CNS [8]. EBV is a human herpes virus, and $90 \%-95 \%$ of the adult human population carries EBV as a chronic latent infection [4]. Most EBV infections are asymptomatic, but EBV sometimes causes a systemic infection or reactivation that may directly involve the CNS [9]. The nervous system is clinically involved in EBV infection in $0.5 \%-7.5 \%$ of individuals, and the most common CNS complications of EBV infection include encephalitis, cerebellitis, meningitis, cranial nerve palsies, and myelitis [7]. However, there are few reports of CNS vasculitis associated with EBV infection. Unfortunately, treatment has not yet been established.

In our case, CSF pleocytosis persisted even after antimicrobial treatment, and considering the negative conversion of EBV DNA, the most likely explanation is that CNS vasculitis occurred after EBV infection. Kim et al. [10] recently reported a patient who was presumed to have developed acute disseminated encephalomyelitis after EBV infection and was treated with rituximab after failing steroid and IV immunoglobulin therapy. As in our case, in the above study, EBV DNA was converted to negative, and the MRI image improved after treatment with rituximab. The pathological development of EBV-related neurological diseases can be immune-mediated, infected,

Figure 3 Diffuse luminal narrowing with dysplastic change of multiple intracranial vessels

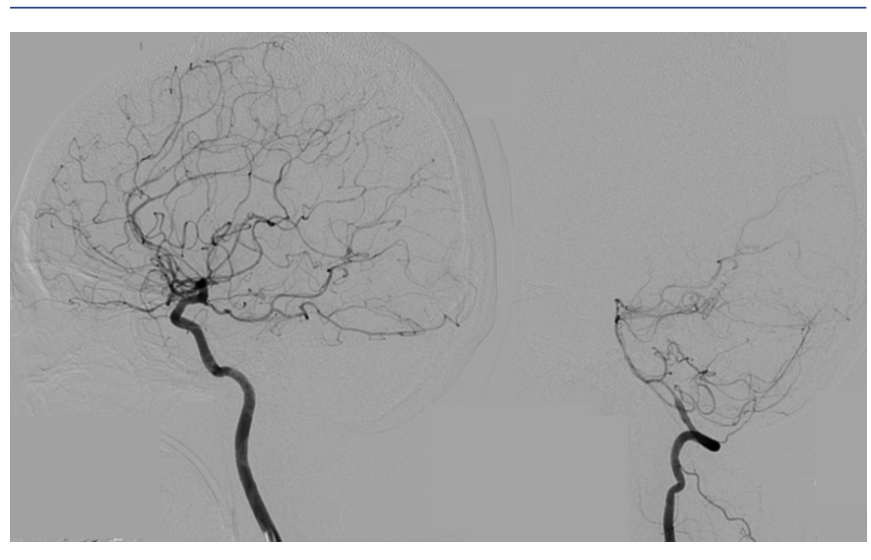


or both [11]. EBV infection may directly or indirectly contribute to the development of the pathogenesis of EBV-associated vasculitis by an immune-mediated reaction. EBV primarily targets B cells via interaction of the viral envelope glycoprotein, and EBV activates primary human B lymphocytes [12]. The preference of EBV for B cells may explain why the anti-CD20 monoclonal antibody rituximab, which targets B cells, has resulted in significant clinical improvements.

Several studies demonstrated a higher incidence of EBV positivity in lymphoproliferative disorder patients than in the general population [13]. A small percentage of these carriers, particularly those with immunodeficiency, develop EBV-positive lymphoproliferative disorders, even though some disorders also develop in the general population [13]. In adults, EBV-positive lymphoproliferative disorders may be caused by dysregulation of the immune response to EBV infection, reduced immunity with aging, and iatrogenic immune suppression [14]. We believe that several autoimmune responses followed sequentially due to changes in immune responses after EBV infection.

Monoclonal gammopathy, whether malignant or of undetermined significance (MGUS), results from clonal proliferation of differentiated plasma cells producing homogeneous whole immunoglobulin or light chain [15]. Reactivation of EBV has been implicated in the pathogenesis of monoclonal gammopathy [16]. Excessive production of abnormal clonal gamma globulins, or paraproteins, causes changes in the circulation by increasing the viscosity [17]. Several studies have been conducted to determine the predictive value of the $\mathrm{M}$ protein as a marker of lymphoid proliferations disease [18], but further studies are still needed.

The patient presented here also had a history of pelvic organ prolapse and umbilical hernia, suggesting that she may have had a connective tissue disorder. Systemic autoimmune diseases (SADs) are a group of connective tissue diseases with diverse, yet overlapping, symptoms and autoantibody development [4]. Because of the relationship between SADs and MGUS, we tested whether the gene was involved or not, but there were no special abnormalities, and no one in the family showed similar symptoms.

In conclusion, we report a lymphoproliferative disorder that appeared after EBV infection in the form of systemic sclerosis and CNS vasculitis. Steroids can be used as first-line treatment, but if the response to steroids is limited, rituximab can be considered as another treatment option for the patient.

\section{Conflicts of Interest}

Kon Chu has been on the editorial board of encephalitis since October 2020. He was not involved in the review process of this case report. No other potential conflicts of interest relevant to this article are reported.

\section{Author Contributions}

Conceptualization: Chu K; Visualization: Lee J; Supervision: Chu K, Lee HS; Writing-original draft and editing: Lee J; Writing-review and editing: all authors.

\section{References}

1. Rajkumar SV, Dispenzieri A, Kyle RA. Monoclonal gammopathy of undetermined significance, Waldenström macroglobulinemia, AL amyloidosis, and related plasma cell disorders: diagnosis and treatment. Mayo Clin Proc 2006;81:693-703.

2. Kyle RA, Larson DR, Therneau TM, et al. Long-term follow-up of monoclonal gammopathy of undetermined significance. N Engl J Med 2018;378:241-249.

3. Shimanovsky A, Alvarez Argote J, Murali S, Dasanu CA. Autoimmune manifestations in patients with multiple myeloma and monoclonal gammopathy of undetermined significance. BBA Clin 2016;6:12-18.

4. Draborg AH, Duus K, Houen G. Epstein-Barr virus in systemic autoimmune diseases. Clin Dev Immunol 2013;2013:535738.

5. Héron E, Fornes P, Rance A, Emmerich J, Bayle O, Fiessinger JN. Brain involvement in scleroderma: two autopsy cases. Stroke 1998;29:719721

6. Cacoub P, Comarmond C, Domont F, Savey L, Saadoun D. Cryoglobulinemia vasculitis. Am J Med 2015;128:950-955.

7. Houen G, Trier NH. Epstein-Barr virus and systemic autoimmune diseases. Front Immunol 2021;11:587380.

8. Salvarani C, Brown RD Jr, Hunder GG. Adult primary central nervous system vasculitis. Lancet 2012;380:767-777.

9. Smatti MK, Al-Sadeq DW, Ali NH, Pintus G, Abou-Saleh H, Nasrallah GK. Epstein-Barr virus epidemiology, serology, and genetic variability of LMP-1 oncogene among healthy population: an update. Front On$\operatorname{col} 2018 ; 8: 211$

10. Kim S, Ahn SJ, Chu K. Epstein-Barr virus-associated acute disseminated encephalomyelitis successfully treated with rituximab: a case report. Encephalitis 2021;1:85-88.

11. Füst G. The role of the Epstein-Barr virus in the pathogenesis of some autoimmune disorders: similarities and differences. Eur J Microbiol Immunol (Bp) 2011;1:267-278.

12. Andrei G, Trompet E, Snoeck R. Novel therapeutics for Epstein-Barr virus. Molecules 2019;24:997. 
13. Hatton OL, Harris-Arnold A, Schaffert S, Krams SM, Martinez OM. The interplay between Epstein-Barr virus and B lymphocytes: implications for infection, immunity, and disease. Immunol Res 2014;58: 268-276.

14. Crombie JL, LaCasce AS. Epstein Barr virus associated B-cell lymphomas and iatrogenic lymphoproliferative disorders. Front Oncol 2019; 9:109.

15. International Myeloma Working Group. Criteria for the classification of monoclonal gammopathies, multiple myeloma and related disorders: a report of the International Myeloma Working Group. Br J Hae- matol 2003;121:749-757.

16. Alabdaljabar MS, Al-Hussain TO, Akhtar M, Conca W, Hussein MH. Rituximab-induced remission in Epstein-Barr virus-associated glomerulonephritis. Kidney Int Rep 2020;5:2109-2113.

17. Kwaan HC. Hyperviscosity in plasma cell dyscrasias. Clin Hemorheol Microcirc 2013;55:75-83.

18. Willrich MA, Katzmann JA. Laboratory testing requirements for diagnosis and follow-up of multiple myeloma and related plasma cell dyscrasias. Clin Chem Lab Med 2016;54:907-919. 